\title{
Structural, surface morphological and optical properties and their correlation with the thickness of spin coated superior quality CdS thin film synthesized using a novel chemical route
}

\author{
Md. Ferdous Rahman ${ }^{1,2}$ • Jaker Hossain ${ }^{1}$ • Abu Bakar Md. Ismail ${ }^{1}$ (D)
}

Received: 14 September 2020 / Accepted: 4 November 2020 / Published online: 7 November 2020

(c) Springer Nature Switzerland AG 2020

\begin{abstract}
Cadmium sulfide (CdS) is considered as a superior buffer/window layer in thin-film solar cells apart from its various applications. The thickness of the buffer/window layer that defines the interface between the absorber layer is very important and needs to be thoroughly investigated for optimized device performance, particularly when a novel synthesis route and deposition technique is used. This manuscript presents the investigation on the various structural, morphological, and optical parameters and their correlation with the thickness of CdS thin film synthesized using a novel thiol-amine cosolvent with the help of Triton-X 100 surfactant. Spin coating technique is used to deposit CdS thin-films having thicknesses ranging from 100 to $300 \mathrm{~nm}$ on a glass substrate. X-ray diffraction (XRD) exposed the polycrystalline nature of the CdS films. All the diffraction peak intensities were found to increase with the thickness. Structural parameters like dislocation density, lattice strain, and crystallites per unit area calculated from the XRD data were found superior to those parameters for $\mathrm{CdS}$ films synthesized through various chemical routes, and the parameters indicated a positive correlation of the degree of crystallinity on the thickness. Similarly, surface morphology and optical properties of CdS films that were investigated by the scanning electron microscope (SEM) and UV-VIS spectrophotometer, were also dependent on film thickness. These results show that CdS thin film with superior crystallinity can be synthesized using thiol-amine cosolvent along with the Triton-X 100 surfactant and deposited by low-cost spin-coating on glass substrate. Moreover, the thickness variation appeared to be a single tool for obtaining application-specific various properties of $C d S$ thin-film.
\end{abstract}

Keywords CdS thin films · Spin coating $\cdot$ Surface morphology $\cdot$ Optical property

\section{Introduction}

Chalcogenide materials such as cadmium sulfide (CdS) have great scientific interest due to its low resistivity, high transmittivity, good chemical stability and large band gap of $2.42 \mathrm{eV}$ at room temperature [1, 2]. CdS thin film have played very interesting role for their photovoltaic applications like photo conducting cells, light emitting diodes and non-linear integrated optical devices [3, 4]. As a window layer, thin films of CdS have been largely used in the application of $\mathrm{CdS} / \mathrm{CdTe}, \mathrm{CdS} / \mathrm{CuInSe}_{2}, \mathrm{CdS} / \mathrm{Cu}_{2} \mathrm{~S}$ and $\mathrm{p}-\mathrm{BaSi}_{2} / \mathrm{n}-\mathrm{CdS}$ high efficiency solar cells [5-10]. Since the deposition technique has great influence on the property of the $\mathrm{CdS}$ thin films, various deposition techniques like Chemical Bath Deposition (CBD) [11], Electrodeposition [12], Spray pyrolysis [13], Chemical Vapor Deposition (CVD) [14], Physical Vapor Deposition (PVD) [15], Sol-gel [16], Molecular Beam Epitaxy (MBE) [17], Electron beam evaporation [18], Pulsed direct current magnetron sputtering [19], close-spaced sublimation [20] and spin coating [21]

\footnotetext{
$\triangle$ Abu Bakar Md. Ismail, ismail@ru.ac.bd | 'Solar Energy Laboratory, Department of Electrical and Electronic Engineering, University of Rajshahi, Rajshahi 6205, Bangladesh. ${ }^{2}$ Department of Electrical and Electronic Engineering, Begum Rokeya University, Rangpur 5400, Bangladesh.
} 
etc. were also investigated. Among these techniques, the spin coating is a popular method for its simplicity, low cost and good reproducibility [21] and that's why spin coating method was chosen for the deposition of CdS thin film in this research.

Numerous experimental works were found to investigate the structural and optical properties of thin films of CdS [22], but very few works were found those investigated the relation between thickness with structural and optical properties of CdS [23], given the fact that for solar cell applications, the thickness of the film is very imperative factor, which influences the junction performance [24]. Under this background we present a detailed investigation by looking into the influence of thickness on the various structural and morphological and optical parameters to find the correlation between the thickness and CdS film quality. It appears that the thickness alone can be tuning tool for the application specific properties of spin-coated CdS thin films.

\section{Materials and methods}

CdS precursor solution were prepared from CdS powder (99.9999\%), Ethylendiamine, and 1,2 Ethanedithiol. All those chemicals were purchased from Sigma Aldrich and were used without further purification. Ethylendiamine and 1,2 Ethanedithiol were blended at a volume proportion of 9:1 as the solvent and $0.5 \mathrm{wt} \%$ CdS powder was mixed with the solvent. After including 1-2 drops of TX-100 surfactant within the $\mathrm{CdS}$ solution the concoction was stirred on a magnetic stirrer for $15 \mathrm{~h}$ at a temperature of $50{ }^{\circ} \mathrm{C}$ that gave a completely dissolved and optically transparent CdS precursor solution. Single layer of CdS film was deposited onto duly cleaned (piranha solution, acetone, isopropyl alcohol and deionized water) and dried soda lime glass (SLG) substrates $\left(1^{\prime \prime} \times 1{ }^{\prime \prime}\right)$ from the prepared CdS precursor solution by spin coating. CdS films of 300 , 200 and $100 \mathrm{~nm}$ were obtained by coating the precursor solution at spinning speeds of 1600, 1800 and $2000 \mathrm{rpm}$ respectively for $45 \mathrm{~s}$. Residual solvents were removed from the as-deposited spin coated CdS films by heating at $90^{\circ} \mathrm{C}$ for $12 \mathrm{~min}$ in an oven (Carbolite: RWF 12/13). CdS films were annealed at $300{ }^{\circ} \mathrm{C}$ in a vacuum chamber for $5 \mathrm{~min}$ that synthesized yellowish colored CdS films.

\section{Results and discussion}

The focus of this article is the thickness dependency of $\mathrm{CdS}$ thin-film properties because the film thickness is considered as an important factor that governs various thin films properties. The thickness of the CdS films was carefully estimated by BRUKER DekTak XTL thickness profilometer. The crystal and structural properties were studied by XRD utilizing the $\mathrm{Cu}$-Ka radiation, while surface morphology was analyzed by the SEM (ZEISS EVO 18). Optical properties were investigated using a UV-VIS spectrophotometer (PG Instruments: T60) in the wavelength ranges of $360-1100 \mathrm{~nm}$.

\subsection{XRD analysis of thickness-dependent crystalline properties of $\mathrm{CdS}$ thin films}

The XRD is considered as a nondestructive technique for studying the crystallographic and structural properties of materials. The XRD spectra of three CdS films having thickness 100, 200 and $300 \mathrm{~nm}$ have been shown in Fig. 1 a. The spectra were obtained by scanning $2 \theta$ in the range of $20^{\circ}-70^{\circ}$. Three diffraction peaks at $2 \theta$ value of $13.20^{\circ}, 15^{\circ}$ and $25^{\circ}$ corresponding to (002), (002)

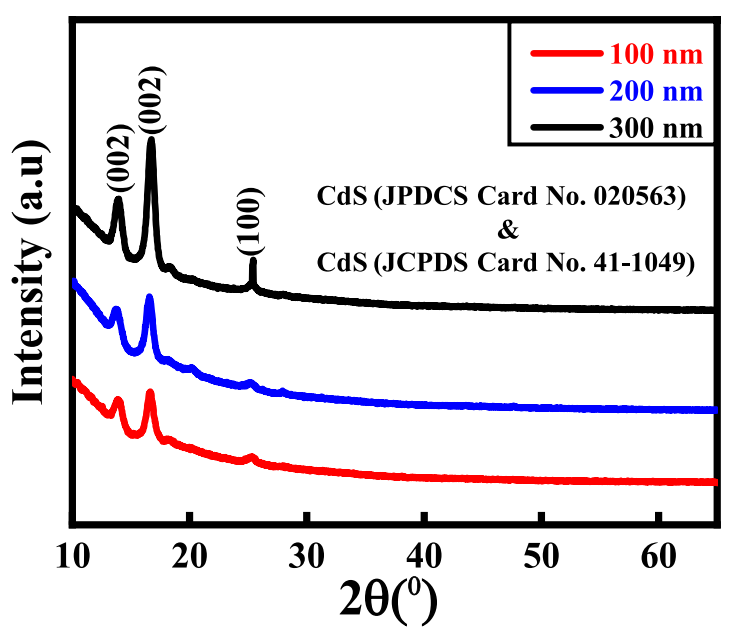

(a)

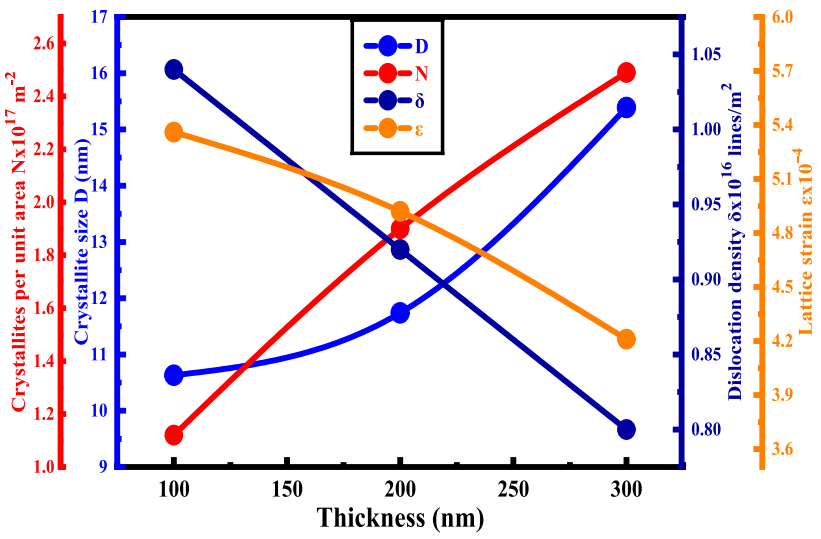

(b)

Fig. 1 a The XRD spectra and $\mathbf{b}$ structural parameters variation with different thicknesses of $\mathrm{CdS}$ thin films and annealed at $300{ }^{\circ} \mathrm{C}$ for $5 \mathrm{~min}$ 
and (100) planes of CdS film were found, which were matched very well with CdS (JPDCS Card No. 020563) and (JCPDS Card No. 41-1049) and agreement with the previous reports [25-29]. CdS films were found polycrystalline dominated by the (002) plane with hexagonal phase. Similar crystallinity can also be found in other reports $[25,30]$. The peak intensity was found to increase with the increase of films thickness, which may be due to the growth of material [31]. When the thickness of CdS films changes $C d$ and $S$ atoms alter their position in the unit cell inducing reorientation and recrystallization of $\mathrm{CdS}$ films that in turn changes the XRD diffraction peak intensity [32].

The influence of thickness of $\mathrm{CdS}$ films on the crystallite size $(D)$, dislocation density $(\delta)$, lattice strain $(\varepsilon)$ and number of crystallites per unit area $(\mathrm{N})$ were also studied and have been shown in Table 1. The crystallite size (D) in the CdS film has been estimated utilizing the Scherrer equation $[33,34]$.

$\mathrm{D}=\frac{0.94 \lambda}{\beta \cos \theta}$

where, $\beta$ is the FWHM in radians, $\lambda$ is the wavelength of the $X$-ray utilized in $\mathrm{nm}$ and $\theta$ is the Corresponding Bragg angle.

From the table 1 and Fig. $1 \mathrm{~b}$, it can be seen that the crystallite size of the film increased from $\sim 10$ to $\sim 15 \mathrm{~nm}$ while the FWHM decreased with film thickness, which confirms the improvement in the level of crystallinity of CdS thin films with thickness. This is attributed to the fact that the grains have the space to develop to their extreme in thicker films $[35,36]$.

The dislocation density, $\delta$ of the CdS film was computed using the Eq. (2), which defines the length of dislocation lines per unit volume of crystal of the films [37, 38].
$\delta=\frac{1}{D^{2}}$

As can be seen from the Fig. $1 \mathrm{~b}$ and Table 1 , with the film thickness the dislocation density of the film decreased from $1.04 \times 10^{16}$ to $0.08 \times 10^{16}$ lines $/ \mathrm{m}^{2}$ indicating that the increase in thickness reduced degree of defect level of $\mathrm{CdS}$ films [37]. The obtained dislocation densities were much lower than previously reported CdS films of similar thicknesses synthesized using a conventional chemical route and deposited using sputtering, chemical-bath (CBD), and close spaced vapour transport (CSVT) techniques [39]. This reduction of dislocation density again supports the better crystallization through the use of our novel chemical route for synthesis. The number of crystallites per unit area $(\mathrm{N})$ that indicates the density of the $\mathrm{CdS}$ film was calculated using Eq. (3) $[40,41]$ and was found to be in the range of $\sim 1.12 \times 10^{17}$ to $\sim 2.49 \times 10^{17}$. The obtained value was higher than the other reported values for the case of chemical bath and electro deposition.

$\mathrm{N}=\frac{t}{D^{3}}$

Another quality factor for crystals is the lattice strain $\varepsilon$. The average value of the $\varepsilon$ was found using the Eq. (4) [37] for various peaks of the CdS films.

$\varepsilon=\frac{\beta}{4 \tan \theta}$

where, $\beta$ is the full width at half maximum (FWHM in radians) of the peak. The value of $\varepsilon$ was found to decrease from $\sim 5.36 \times 10^{-4}$ to $\sim 4.21 \times 10^{-4}$ with film thickness indicative of reduced degree of irregularity and improved crystallinity level [42]. From these structural investigations it is possible to conclude that the CdS films having good crystallinity and structural parameters can be synthesized using a simple spin-coating technique and the

Table.1 Structural parameters

\begin{tabular}{|c|c|c|c|c|c|c|c|c|c|c|c|}
\hline $\begin{array}{l}\text { Thickness } \\
(\mathrm{nm})\end{array}$ & $2 \theta\left(^{0}\right)$ & hkl & $\begin{array}{l}\text { FWHM } \\
\beta(\mathrm{rad})\end{array}$ & $\begin{array}{l}\text { D } \\
(\mathrm{nm})\end{array}$ & $\begin{array}{l}\text { Avg } \\
(\mathrm{D}) \\
(\mathrm{nm})\end{array}$ & $\begin{array}{l}\delta \times 10^{16} \\
\text { lines } / \mathrm{m}^{2}\end{array}$ & $\begin{array}{l}\text { Avg } \\
\delta \times 10^{16} \text { lines } / \mathrm{m}^{2}\end{array}$ & $\begin{array}{l}\mathrm{N} \times 10^{17} \\
\text { Per unit area }\end{array}$ & $\begin{array}{l}\text { Avg } \\
\mathrm{N} \times 10^{17}\end{array}$ & $\varepsilon \times 10^{-4}$ & $\begin{array}{l}\text { Avg } \\
\varepsilon \times 10^{-4}\end{array}$ \\
\hline \multirow[t]{4}{*}{100} & 13.2 & 002 & 0.0164 & 8.90 & 10.63 & 1.26 & 1.04 & 1.42 & 1.12 & 4.74 & 5.36 \\
\hline & 15 & 002 & 0.0171 & 8.55 & & 1.3 & & 1.60 & & 5.63 & \\
\hline & 25 & 100 & 0.0103 & 14.4 & & 0.48 & & 0.33 & & 5.71 & \\
\hline & 13.2 & 002 & 0.0159 & 9.19 & & 1.18 & & 2.50 & & 4.59 & \\
\hline \multirow[t]{3}{*}{200} & 15 & 002 & 0.0162 & 9.01 & 11.74 & 1.23 & 0.92 & 2.70 & 1.90 & 5.34 & 4.92 \\
\hline & 25 & 100 & 0.0087 & 17.0 & & 0.35 & & 0.40 & & 4.84 & \\
\hline & 13.2 & 002 & 0.0157 & 9.29 & & 1.16 & & 3.74 & & 4.54 & \\
\hline \multirow[t]{2}{*}{300} & 15 & 002 & 0.0155 & 9.42 & 15.39 & 1.13 & 0.80 & 3.59 & 2.49 & 5.11 & 4.21 \\
\hline & 25 & 100 & 0.0054 & 27.5 & & 0.13 & & 0.15 & & 2.99 & \\
\hline
\end{tabular}


crystallinity of the spin-coated CdS film can be tuned by the film thickness.

\subsection{Surface morphology investigation of CdS thin films using SEM}

SEM was utilized to study the surface feature and the crystal growth of CdS films. Figure 2 presents the SEM micrographs of the top view of CdS thin films of various thicknesses. CdS thin films were found to be well covered on the substrate and free from microscopic defects such as pinholes, crack or peeling. All films have homogeneous, smooth and consistent surface with spherical crystallites. This observed symmetry might be attributable to enormous surface energy of these crystallites and appear great attachment to the film surface because of the effect of TX-100 surfactant, which has been already reported $[43,44]$. Cauliflowers like globules appeared in the thicker CdS film surface, which matched well with the previous report [45]. Another important parameter, the coalescences play a principle part in CdS films when the thickness is increased. Coalescences are believed to be created due to add atoms ( $\mathrm{Cd}$ and S). These atoms interchange their position when re-crystallization of grains happens that encouraged the reorientation of the overall microstructure $[46,47]$. The CdS thin film compactness increases and roughness decreases with increases in film thickness, which indicates crystallinity improvement of the films with thickness as was seen from the XRD analysis [47].

\subsection{Investigation on the thickness dependent optical properties of $\mathrm{CdS}$ thin films}

The optical properties were mainly studied by looking at the UV-VIS transmission properties of the films. Figure 3 shows the transmittance (T\%) and reflectance (R\%) spectra in the wavelength range $360-1100 \mathrm{~nm}$ of spin coated $\mathrm{CdS}$ films annealed at $300^{\circ} \mathrm{C}$ for $5 \mathrm{~min}$. It appeared that all CdS films were highly transparent in the visible area. Average optical transmittance and reflectance were found $(\% \mathrm{~T})>65 \%$ and $(\% \mathrm{R})<20 \%$ in the near-infrared solar spectrum, which is important for good crystallinity of the CdS films [48]. However, the transmittance of CdS film was rapidly decreased in the transparent area $(\lambda \geq 550 \mathrm{~nm})$ with increasing reflectance. It is important to mention here that high transmittance is one of the vital properties for window materials in the visible area [49]. As was expected, for all the CdS films the transmittance (T\%) decreases and Reflectance (R\%) increases with increasing film thickness. However, higher films thickness provides a thick and compact film surface having improved crystallinity [50].

The absorption coefficient (a) was computed utilizing the Eq. (5) [51].

SN Applied Sciences

A SPRINGER NATURE journal

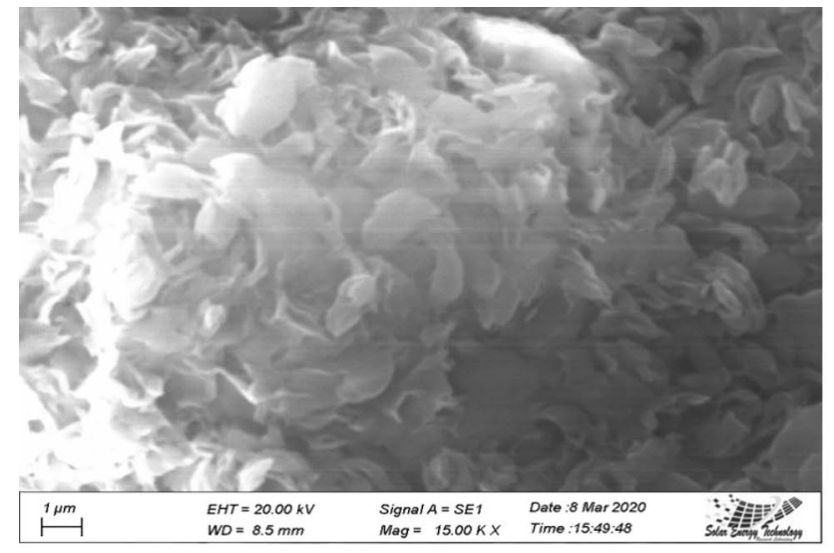

(a)

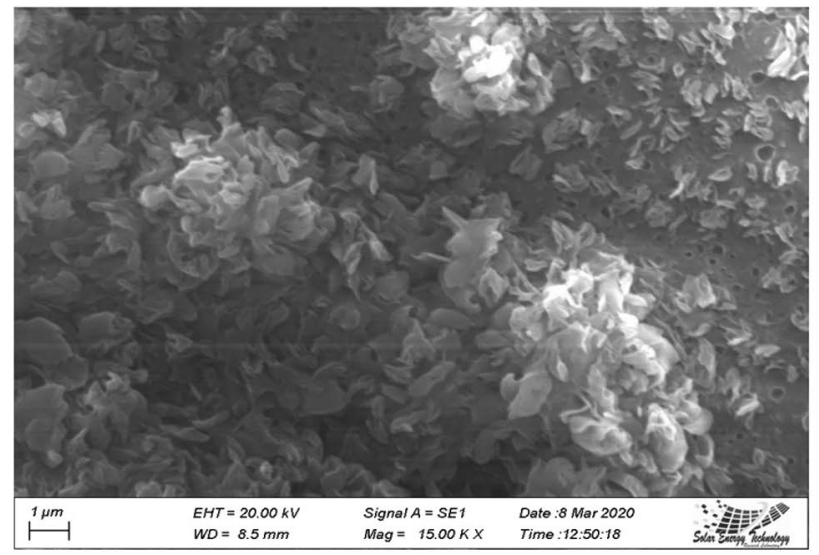

(b)

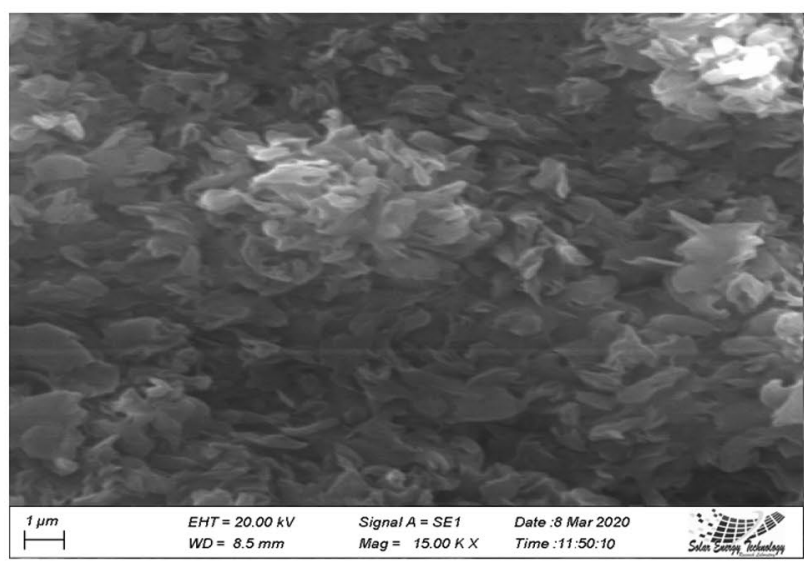

(c)

Fig. 2 The SEM micrograph of CdS thin films with various thicknesses a $100 \mathrm{~nm}, \mathbf{b} 200 \mathrm{~nm}$ and $\mathbf{c} 300 \mathrm{~nm}$

$\alpha=\frac{\ln \left(\frac{100}{T}\right)}{d}$

The absorption coefficients of CdS films at different photon energies with varying thickness are shown inset 


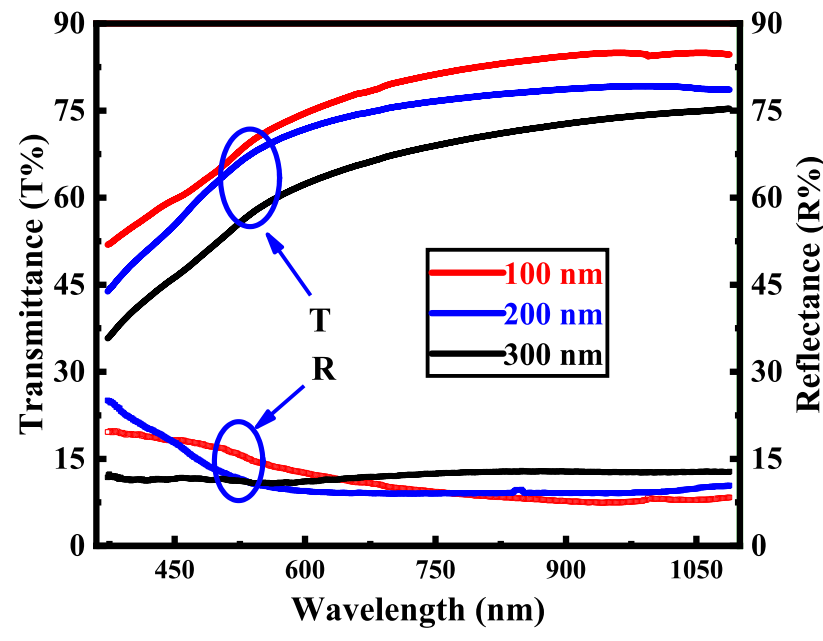

Fig. 3 The transmittance and reflectance spectra of CdS films

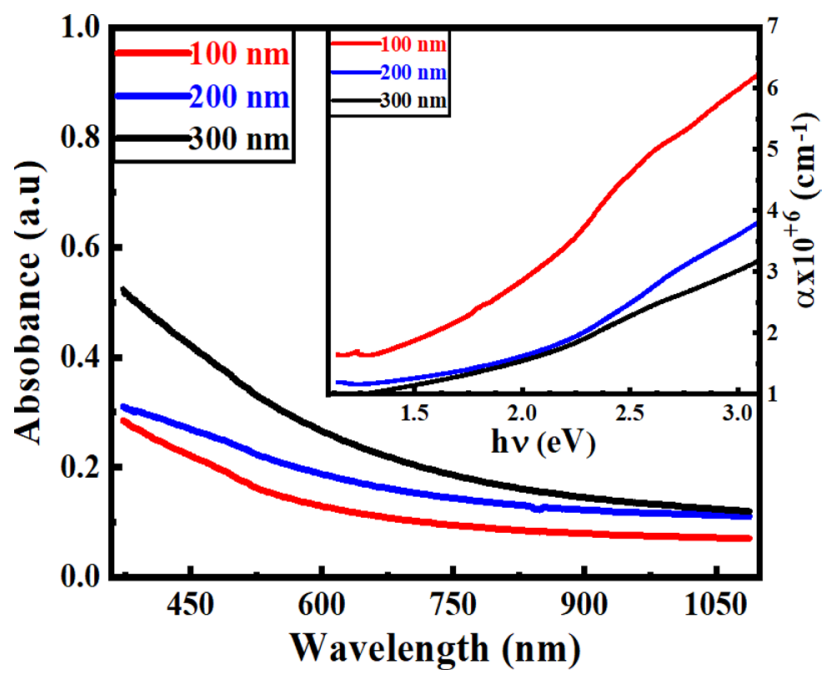

Fig. 4 The absorbance (A) and absorption coefficient (a) spectra of CdS thin films

in Fig. 4. From absorption coefficients spectra, we examined that the thicker films appeared lower a value at high energy area than the thinner films. This result may be owing to increasing crystallites size with film thickness and these larger crystallite sizes provide greater unfilled inter-granular volume so the absorption coefficient per unit thickness is diminished [52].

\subsubsection{Band gap and Urbach energy of $\mathrm{CdS}$ thin films with various thicknesses}

Using the Tauc relationship the computed optical band gap has been shown in Fig. 5 and has been tabulated in Table 2. The direct band gap of CdS thin films was obtained by extrapolating the straight line of $(a h v)^{2}$

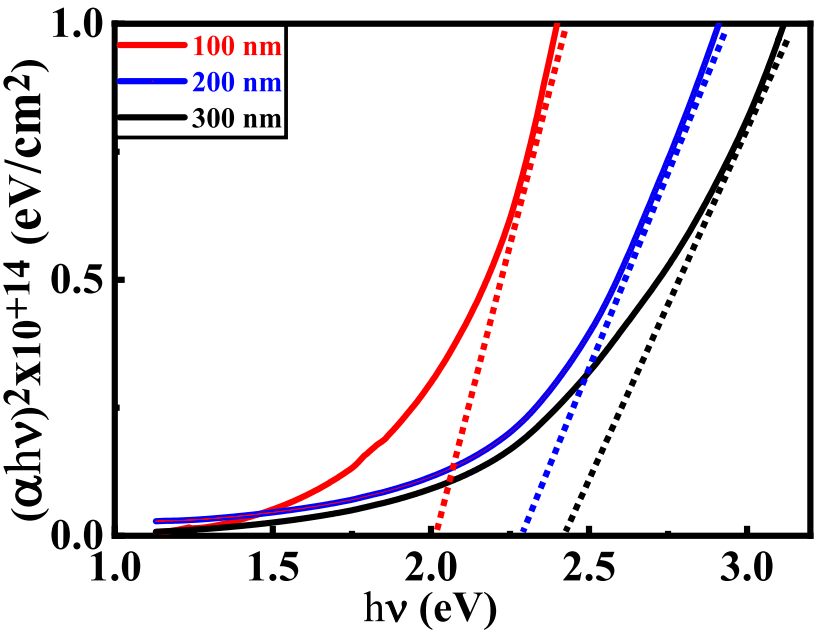

Fig. 5 The plot of $(a h v)^{2}$ with hu for CdS thin films with various thicknesses and annealed at $300^{\circ} \mathrm{C}$ for $5 \mathrm{~min}$

Table 2 Band gap and crystal size variation with different thicknesses of CdS thin films

\begin{tabular}{lll}
\hline $\begin{array}{l}\text { CdS film thickness } \\
(\mathrm{nm})\end{array}$ & Crystal size $(\mathrm{nm})$ & Band gap $(\mathrm{eV})$ \\
\hline 100 & 10.63 & 2.10 \\
200 & 11.74 & 2.31 \\
300 & 15.39 & 2.42 \\
\hline
\end{tabular}

versus (hv) plot to $a=0$, as illustrated in Fig. 5. Thus, the originated band gap ( $\mathrm{Eg}$ ) was determined to be 2.1-2.42 eV with increasing thickness.

As shown in Table 2, although the crystallite size increases with increase in film thickness, it is interesting to note that the optical band gap also increases with film thickness. Usually the band gap decreases with the thickness, but band gap shows dependency on the deposition technique and process [52]. There are many reports on increase of band gap with thickness [54-56] and $\mathrm{pH}$ $[57,58]$, particularly for chemical deposition technique like dip-coating and spray-pyrolysis. Increase in band gap with thickness is believed to be due to the improvement of crystallinity [58].

The width of the extension of localized deformity states in the band gap is known as Urbach energy $E_{u}$, and this defect states bolt within the energized electrons, which break off their direct transition to the conduction band and enlarge the forbidden gap [59]. This Urbach energy $\left(E_{U}\right)$ is additionally related to the structural disorder within the films [60]. $E_{u}$ was calculated from the absorption spectra using the following equation [61] and was shown in Fig. 6 a. 
Fig.6 The a Urbach energy, $\mathrm{E}_{\mathrm{u}}$ and $\mathbf{b}$ variation of $\mathrm{E}_{\mathrm{g}}$ and $\mathrm{E}_{\mathrm{u}}$ curves of $\mathrm{CdS}$ thin films with various thicknesses

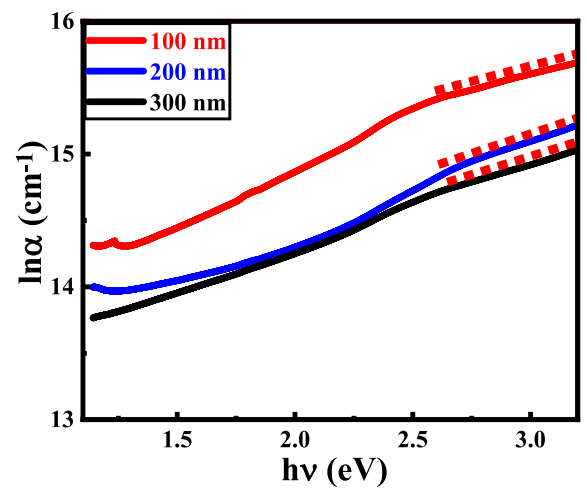

(a)

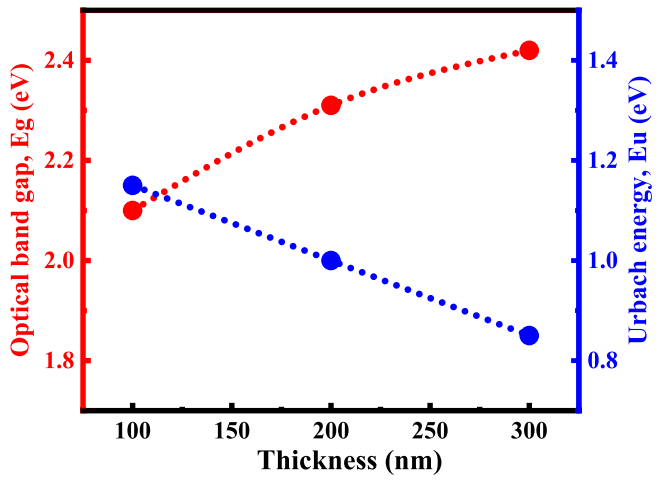

(b) $\alpha=\alpha_{0} \exp \frac{\mathrm{hv}}{\mathrm{Eu}}$

$\ln \alpha=\ln \alpha_{0}+\frac{\mathrm{hv}}{\mathrm{Eu}}$

However, the Urbach energy is computed by plotting In(a) with hv as appeared within the complementary of the slope of the obtained straight lines is utilized to find out the Urbach energy, $E_{U}$. Figure $6 \mathrm{~b}$ shows the change of $\mathrm{Eg}$ and $\mathrm{Eu}$ with thicknesses of CdS film, where it can be found that with the increasing thickness of CdS film change in Eg was opposite to that of Eu. This relationship ensures the enhancement of crystalline properties of the CdS films $[62,63]$ that was responsible for the obtained XRD peak intensity [57]. Again, it was in agreement of our XRD investigation on CdS films.

\subsubsection{Refractive index and extinction coefficient of CdS thin films}

The refractive index, $\mathrm{n}$ and extinction coefficient, $\mathrm{k}$ of $\mathrm{CdS}$ film are very important parameters when we are discussing the application of CdS films as window/buffer layer. The influence of film thickness on $\mathrm{n}$ and $\mathrm{k}$ needs to be understood in details as these parameters are strongly associated with the electronic polarization of particles for the optical materials [64].

The reflectance $R$ (=1 - absorbance-transmittance) [65] of a film having a complex refractive index of $n^{*}(=n+i k)$ is given by [66]

$R=\frac{\left(n^{*}-1\right)^{2}}{\left(n^{*}+1\right)^{2}}=\frac{(n-1)^{2}+k^{2}}{(n+1)^{2}+k^{2}}$

The absorption coefficient a was calculated using Beer Lambert's formula [67] and the extinction coefficient of the CdS film from the following equation [34]. $\mathrm{k}=\frac{\alpha \lambda}{4 \pi}$

The refractive index $\mathrm{n}$ was found by solving Eq. (8)

$n=\frac{(1+R)+\left[(1+R)^{2}-(1-R)^{2}-\left(1-k^{2}\right)\right]^{1 / 2}}{(1-R)}$

Figure7a shows the extinction coefficient $\mathrm{k}$ calculated using Eq. (9) and plotted with photon energy. Extinction coefficient was found to increases with the photon energy. In the NIR region the value of $k$ decreases with increase in film thicknesses. The maximum and minimum values of $\mathrm{k}(\sim 0.2$ and $\sim 0.07$ respectively) very similar to earlier report [68]. Additional absorption of light happens at the grain boundaries in the polycrystalline films, when values of $\mathrm{k}$ become non-zero for photon energies smaller than the basic absorption edge [69]. However, the extinction coefficients decreased with CdS film thickness indicative of superior optical properties of CdS layers to be applied as a window/buffer layer in thin film solar cells.

Applying Eq. (10) the refractive index was computed and plotted with photon's energy, which is shown in Fig. 7b. From the Fig. 7a, b quick increase of refractive index with photon energy and an oscillatory behavior in the visible spectrum are evident. In the higher photon energy, a slight decrease of refractive index was seen with the thickness, which may be due to the progressive inner reflection or trapping of energy inside the grain boundaries. The average refractive index was found about $\sim 2.5$, which is good agreement with the earlier report [69].

\subsubsection{Complex dielectric constant of CdS thin films with different thicknesses}

The complex dielectric constant of the films, whose real portion $\left(\varepsilon_{\mathrm{r}}\right)$ is strongly related with the refractive index and the imaginary part $\left(\varepsilon_{\mathrm{i}}\right)$ is associated with the absorption of 
Fig.7 The a extinction coefficient and $\mathbf{b}$ refractive index against photon energy of spin coated

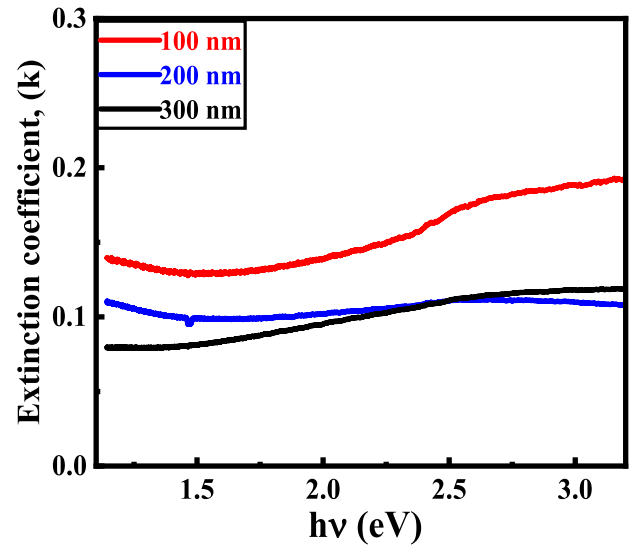

(a)

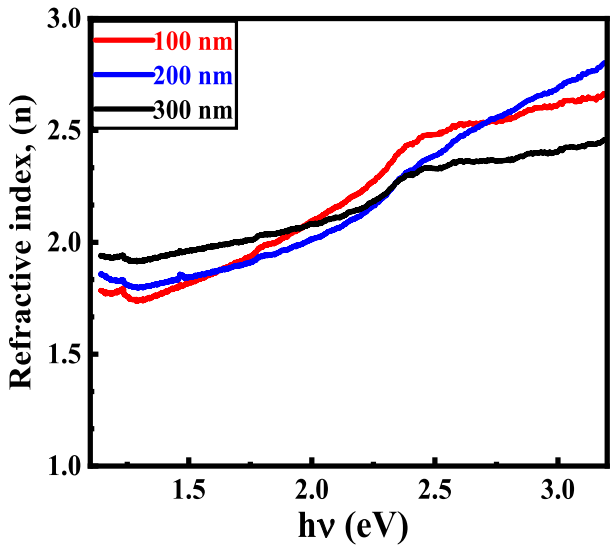

(b) light of material, was also investigated. The real part of the dielectric constant is found using the Eq. (11) [38]

$\varepsilon_{\mathrm{r}}=\mathrm{n}^{2}-\mathrm{k}^{2}$

Figure 8a demonstrates the relation between $\varepsilon_{\mathrm{r}}$ against the photon's energy. It can be found that the $\varepsilon_{\mathrm{r}}$ increased with photon's energy [69]. An oscillatory behavior of $\varepsilon_{\mathrm{r}}$ in the visible range similar like refractive index between the value of $\sim 5<\varepsilon_{\mathrm{r}}<\sim 8$ was also observed.

The imaginary portions of the dielectric constant are computed using the following equation [38]

$\varepsilon_{\mathrm{i}}=2 \mathrm{nk}$

Figure $8 \mathrm{~b}$ also illustrates the connection between $\varepsilon_{\mathrm{i}}$ and hu, which clearly shows that $\varepsilon_{\mathrm{i}}$ increases rapidly with hu [3] and slightly decreases with film thickness. It has been shown the same behavior of $k$ and in the visible area the value of the imaginary part of the dielectric constant is approximately constant between $\sim 0.30$ and $\sim 0.80$.

\section{Conclusions}

Superior quality thin films of cadmium sulfide (CdS) having thickness $100 \sim 300 \mathrm{~nm}$ were successfully synthesized through the use thiol-amine co-solvent along with TX-100 surfactant and deposited on to soda lime glass (SLG) substrates by easy and inexpensive spin coating method. The structural, morphological and optical properties of $\mathrm{CdS}$ thin films were found to reliant strongly on film thickness. These results imply that only thickness variation might be an important tool for obtaining application specific various properties of $\mathrm{CdS}$ thin-films.
Fig.8 The complex dielectric constant with hu of CdS films a real part and $\mathbf{b}$ imaginary part

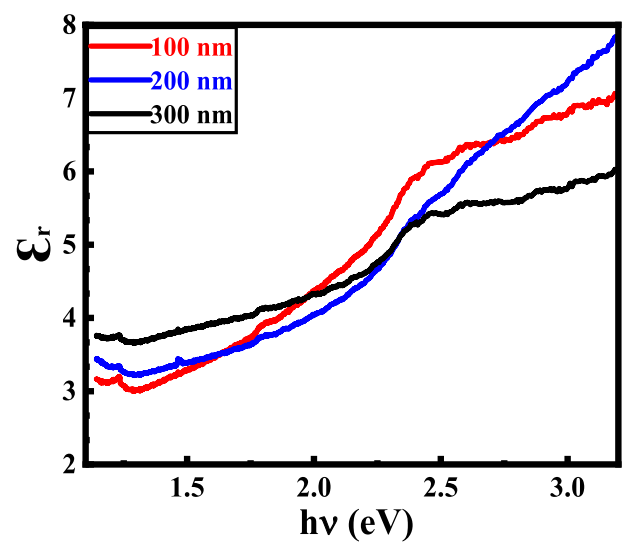

(a)

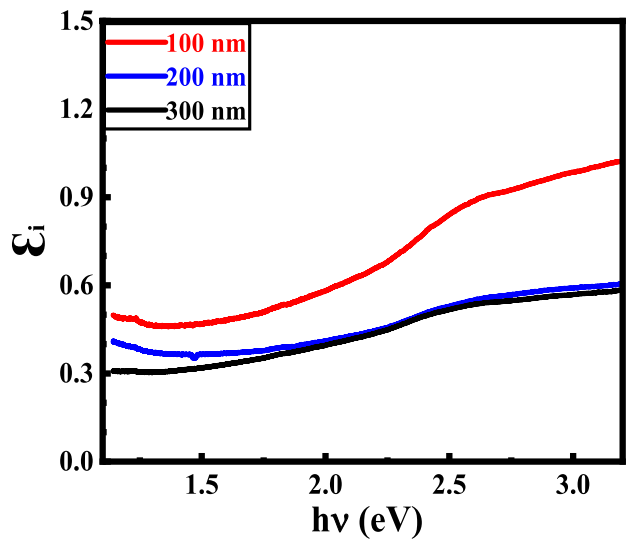

(b) 
Acknowledgments The authors thank the Bangladesh Council of Scientific and Industrial Research (BCSIR), Dhaka 1205, Bangladesh, for using their XRD and SEM facilities.

Author contributions Abu Bakar Md. Ismail and Jaker Hossain conceived the original idea. Md. Ferdous Rahman and Jaker Hossain synthesized the $\mathrm{CdS}$ samples and carried out the experiments. All authors discussed the results and contributed to the final manuscript. Md. Ferdous Rahman prepared the manuscript with support from Abu Bakar Md. Ismail and Jaker Hossain. Abu Bakar Md. Ismail and Jaker Hossain jointly supervised the project.

Data Availability Data will be made available when required.

\section{Compliance with ethical standards}

Conflicts of Interest The authors declare that there is no conflict of interest regarding the publication of this paper.

\section{References}

1. Tummala R, Guduru RK, Mohanty PS (2012) Solution precursor plasma deposition of nanostructured CdS thin films. Mat Res Bull 47:700

2. Senthamilselvi V, Ravichandran K, Saravanakumar K (2013) Influence of immersion cycles on the stoichiometry of CdS films deposited by SILAR technique. J Phys Chem Solids 74:65

3. Kumar SG, Rao KSRK (2014) Physics and chemistry of CdTe/CdS thin film heterojunction photovoltaic devices: fundamental and critical aspects. Energy Environ Sci 7:45

4. Sentil K, Mangalaraj D, Narayandass SK (2001) Structural and optical properties of CdS thin films. Appl Surf Sci 169-170:476

5. Kuddus A, Rahman MF, Ahmmed S, Hossain J, Ismail ABM (2019) Role of facile synthesized V2O5 as hole transport layer for CdS/ CdTe heterojunction solar cell: validation of simulation using experimental data. Superlattices Microstruct 132:106168

6. Moon, M. M. A., Rahman, M.F, Ismail, A.B.M (2018) Optimization of active region thickness of $\mathrm{CdTe} / \mathrm{CdS}$ thin film superstrate solar cell to achieve $\sim 25 \%$ efficiency A simulation approach. International Conference on Computer Communication Chemical Material and Electronic Engineering (IC4ME2), pp 1-4. https:// doi.org/10.1109/ic4me2.2018.8465600.

7. Kemell M, Ritala M, Leskela M (2005) Thin film deposition methods for CulnSe2 solar cells. Crit Rev Solid State Mater Sci 30:1

8. Mohammed, W.F., Al-Tikriti, M. (2015) Novel electronic approach for efficient energy harvesting from $\mathrm{Cu}_{2} \mathrm{~S} / \mathrm{CdS}$ solar cell, 2015 IEEE 12th International Multi-Conference on Systems, Signals \& Devices (SSD15), 1-8.

9. Moon MMA, Ali MH, Rahman MF, Kuddus A, Hossain J, Ismail ABM (2020) Investigation of thin-film p-BaSi2/n-CdS heterostructure towards semiconducting silicide based high efficiency solar cell. Phys Scr 95:035506

10. Biplab SRI, Ali MH, Moon MMA, Pervez MF, Rahman MF, Hossain $J$ (2020) Performance enhancement of CIGS-based solar cells by incorporating an ultrathin BaSi2 BSF layer. J Comput Electron 19:342

11. Li J (2015) Preparation and properties of CdS thin films deposited by chemical bath deposition. Ceram Int 41:S376

12. Kamila Z, Magdalena S (2011) Electrodeposition of CdS from acidic aqueous thiosulfate solution-investigation of the mechanism by electrochemical quartz microbalance technique. Electrochim Acta 56:5731
13. Zhu G, LvT, Pan L (2011) All spray pyrolysis deposited CdS sensitized $\mathrm{ZnO}$ films for quantum dot-sensitized solar cells. J Alloys Compd 509:362

14. Fainer NI, Kosinova ML, Rumyantsev YM, Salman EG, Kuznetsov FA (1996) Growth of PbS and CdS thin films by low-pressure chemical vapour deposition using dithiocarbamates. Thin Solid Films 280:16

15. Aboul-Enein S, Badawi MH, Ghali M, Hassan G (1998) Preparation and properties of CdS thin films prepared on cold substrate as a window layer for solar cells. Renew Energy 14:113

16. Khan M, Khan MS, Aziz A, Rahman SA, Khan ZR (1894) Spectroscopic studies of sol-gel grown CdS nanocrystalline thin films for optoelectronic devices. Mater Sci Semicond Process 2013:16

17. Boieriu P, Sporken R, Xin Y, Browning ND, Sivananthan S (2000) Wurtzite CdS on CdTe grown by molecular beam epitaxy. J Elect Mat 29:718

18. Sivaramamoorthy $\mathrm{K}$, Bahadur SA, Kottaisamy M, Murali KR (2010) Properties of CdS films deposited by the electron beam evaporation technique. J Alloys Compd 503:170

19. Kaminski, P. M.; Lisco, F.; Abbas, A.; Bowers, J.W.; Claudio, G.; Walls, J.M (2014). Oxygenated CdS window layers for thin film CdTe photovoltaic's by pulsed DC magnetron sputtering, IEEE 40th Photovoltaic Specialist Conference (PVSC), 1626.

20. Rabeel $Z$ et al (2017) Comparative study of CdS Nano films deposited by chemical bath and close spaced sublimation techniques. J Adv Nanomat 2:113

21. Rahman MF et al (2020a) A novel synthesis and characterization of transparent CdS thin films for $\mathrm{CdTe/CdS}$ solar cell. Appl Phys A 126:145

22. Senthil K, Mangalaraj D, Narayandass SK (2001) Structural and optical properties of CdS thin films. Appl Surf Sc 169-170:476

23. Rondiya SR et al (2016) Film thickness effects on morphology, optical and structural properties of chemical bath deposition grown CdS thin films for solar cell applications. Adv Sc Lett 22:854

24. Enriquez JP, Mathew $X$ (2003) Influence of the thickness on structural, optical and electrical properties of chemical bath deposited CdS thin films. Sol Ener Mat Sol Cells 76:313

25. Bagnall DM, Ullrich B, Qiu XG, Segawa Y (1999) Microcavity lasing of optically excited cadmium sulfide thin films at room temperature. Opt Lett 24:1278

26. Mishra RK, Vedeshwar AG, Tandon RP (2012) The role of glassviscosity on the growth of semiconductor quantum dots in glass matrices. J Appl Phys 111:094315

27. Bosio A, Rosa G, Romeo N (2018) Past, present and future of the thin film CdTe/CdS solar cells. Sol Ener. https://doi. org/10.1016/j.solener.2018.01.018

28. Rao BS, Kumar BR, Reddy VR, Rao TS (2011) Preparation and characterization of CdS nanoparticles by chemical Co-precipitation technique. Chalco Lett 8:177

29. Soltani N et al (2012) Visible light-induced degradation of methylene blue in the presence of photocatalytic ZnS and CdS nanoparticles. Int J Mol Sci 13:12242

30. Memarian N, Rozati SM, Concina I, Vomiero A (2017) Deposition of nanostructured $\mathrm{CdS}$ thin films by thermal evaporation method: effect of substrate temperature. Materials 10:773

31. Maneeshya LV, Anitha VS, Thomas PV, Joy K (2015) Thickness dependence of structural, optical and luminescence properties of $\mathrm{BaTiO} 3$ thin films prepared by RF magnetron sputtering. J Mater Sci: Mater Electron. https://doi.org/10.1007/s1085 4-015-2781-1

32. Rahman M et al (2019) Unraveling the electrical properties of solution-processed copper iodide thin films for $\mathrm{Cul} / \mathrm{n}$-Si solar cells. Mater Res Bull 118:110518 
33. Kariper IA (2018a) A new route to synthesize MnSe thin films by chemical bath deposition method. Mater Res 21:e20170215. https://doi.org/10.1590/1980-5373-MR-2017-0215

34. Ashok A et al (2020) Comparative studies of CdS thin films by chemical bath deposition techniques as a buffer layer for solar cell applications. J Mater Sci: Mater Electron. https://doi. org/10.1007/s10854-020-03024-3

35. Dhanam M, Prabhu RR, Manoj PK (2008) Investigations on chemical bath deposited cadmium selenide thin films. Mat Chem Phys 107:289

36. Chander S, Dhaka MS (2015) Optimization of physical properties of vacuum evaporated CdTe thin films with the application of thermal treatment for solar cells. Mat Sc Semi Process 40:708

37. Aydın F, Tezel FM, Kariper IA (2019) Optical, electrical, structural and magnetic properties of BiSe thin films produced by CBD on different substrates for optoelectronics applications. Mater Res Express 6:016425. https://doi.org/10.1088/2053-1591/aae9bf

38. Islam MA et al (2013) Comparison of structural and optical properties of CdS thin films grown by CSVT. CBD Sputter Tech Energy Proced 33:203

39. Tezel FM, Kariper IA (2018) A new process to synthesize CrSe thin films with nanosize by CBD method. Mater Res Express. https:// doi.org/10.1088/2053-1591/aaf593

40. Kariper IA (2018b) Optical properties and surface energy of tellurium oxide thin film. J Opt 47:504-510. https://doi.org/10.1007/ s12596-018-0485-7

41. Abubaker A et al (2013) Influence of substrate temperature on the structural, optical and electrical properties of CdS thin films deposited by thermal evaporation. Results in Phys 3:173

42. Rahman MF et al (2020b) Effect of Triton X-100 surfactant on thiol-amine cosolvents assisted facile synthesized CdS thin films on glass substrate by spin coating method. SN Appl Sci 2:590

43. Ballipinar F, Rastogi AC (2017) High transmittance cadmium oxysulfide $\mathrm{Cd}(\mathrm{S}, \mathrm{O})$ buffer layer grown by triton $\mathrm{X}-100$ mediated chemical bath deposition for thin-film heterojunction solar cells. J Appl Phys 121:035302

44. Metin H, Erat S, Durmus S, Ari M (2010) Annealing effect on CdS/ $\mathrm{SnO} 2$ films grown by chemical bath deposition. Appl Surf Sc 256:5076

45. Shah NA, Sagar RR, Mahmood W, Syed AA (2012) Cu-doping effects on the physical properties of cadmium sulfide thin films. J Alloys Compd 512:185

46. Mahmood W et al (2018) Optical and electrical studies of CdS thin films with thickness variation. Optik 158:1558

47. Kumar $S$ et al (2012) CdS nanofilms: effect of film thickness on morphology and optical band gap. J App Phy 112:123512

48. Ikhmayies, S. J. (2014). The influence of thickness on the optical parameters of thermally evaporated CdS thin films, TMS 2014 Supplemental Proceedings, 383.

49. Mohamed HA (2015) Optimized conditions for the improvement of thin film CdS/CdTe solar cells. Thin Sol Films 589:72

50. Rahman MF et al (2020c) A novel CdTe ink-assisted direct synthesis of CdTe thin films for the solution-processed CdTe solar cells. J Mater Sci 55:7715

51. Diwan MH (2014) Effect of film thickness on optical and structural properties of CdS thin films prepared by spray pyrolysis. Diyala J Pure Sc 10:158

52. Li et al (2017) Effects of deposition methods and processing techniques on band gap, interband electronic transitions, and optical absorption in perovskite $\mathrm{CH}_{3} \mathrm{NH}_{3} \mathrm{Pbl}_{3}$ films. Appl Phys Lett 111:011906

53. Dhawale DS et al (2011) Synthesis and characterizations of CdS nanorods by SILAR method: effect of film thickness. J Mater Sci 46:5009

54. Ikhmayies SJ, Ahmad-Bitar RN (2013) A study of the optical bandgap energy and urbach tail of spray-deposited CdS: In thin films. J Mater Res Technol 2:221

55. Ikhmayies SJ, Ahmad-Bitar RN (2008) Effect of film thickness on the electrical and structural properties of CdS: In thin films. Am J Appl Sci 5:1141-1143

56. Kariper IA et al (2011) The structural, electrical and optical properties of $\mathrm{CdS}$ thin films as a function of $\mathrm{pH}$. Mater Chem Phys 129:183-188

57. Kariper IA et al (2012) Effect of $\mathrm{P}^{\mathrm{H}}$ on the physical properties of CdS thin films deposited by CBD. Chalcogenide Lett 9:27-40

58. Akshay VR, Arun B, Mandal G, Vasundhara M (2019) Visible range optical absorption, urbach energy estimation and paramagnetic response in $\mathrm{Cr}$-doped $\mathrm{TiO} 2$ nanocrystals derived by a sol-gel method. Phys Chem Chem Phys 21:12991

59. Ayieko CO et al (2016) Structural and optical characterization of nitrogen-doped $\mathrm{TiO} 2$ thin films deposited by spray pyrolysis on fluorine doped tin oxide (FTO) coated glass slides. Int J Ener Engg 2:67

60. Bedia A et al (2015) Morphological and optical properties of $\mathrm{ZnO}$ thin films prepared by spray pyrolysis on glass substrates at various temperatures for integration in solar cell. Energy Proced 74:529

61. Hassanien AS, Akl AA (2016) Effect of Se addition on optical and electrical properties of chalcogenide CdSSe thin films. Superlat Microstruc 89:153

62. Abdel-Baki M, Abdel-Wahab FA, El-Diasty F (2012) One-photon band gap engineering of borate glass doped with $\mathrm{ZnO}$ for photonics applications. J Appl Phys 111:073506

63. Hassanien AS, Akl AA (2015) Influence of composition on optical and dispersion parameters of thermally evaporated non-crystalline Cd50S50-xSex thin films. J. Alloys Compd. 648:280-290

64. Okorie O, Buba ADA, Ramalan AM (2017) Optical and dielectric properties of cadmium sulphide thin film grown using chemical bath deposition technique. IOSR J. Appl. Phys. 9:82

65. Babkair SS, Al-Twarqi NM, Ansari AA (2011) Optical characterization of CdTe films for solar cell applications, karachi univ. J Sc 39:1-5

66. Nadeem MY, Ahmed W (2000) Optical properties of ZnS thin films. Turk J Phys 24:651

67. Tepehan F, Özer N (1993) A simple method for the determination of the optical constants, $n$ and $k$ of cadmium sulfide films from transmittance measurements. Sol Energy Mater Sol Cells 30:353

68. Sahay PP, Nath RK, Tewari S (2007) Optical properties of thermally evaporated CdS thin films. Cryst Res Technol 42:275

69. Das SK et al (2019) Simulation study of optical properties of transparent CdS thin film using the sellmeier empirical dispersion formula. Int J Photon Opt Tech 5:4

Publisher's Note Springer Nature remains neutral with regard to jurisdictional claims in published maps and institutional affiliations. 